\title{
The neuropathology of canine cerebral babesiosis compared to human cerebral malaria
}

\author{
Andrew Leisewitz ${ }^{1 *}$, Gareth Turner ${ }^{2}$, Sarah Clift $^{3}$, Anne Pardini ${ }^{1}$ \\ From Challanges in malaria research: Core science and innovation \\ Oxford, UK. 22-24 September 2014
}

\section{Background}

The favoured animal model of cerebral malaria is an artificial host-parasite combination caused by Plasmodium berghei in inbred mouse strains [1]. Canine babesiosis caused by natural infection in dogs with Babesia rossi causes cerebral disease in some cases [2]. This disease demonstrates both similarities and differences to human malarial and comparisons may be of value in elucidating the pathogenesis of this serious complication in both hosts [3].

\section{Materials and methods}

Post mortem brains collected from 50 natural cases of canine babesiosis showing clinical signs of cerebral involvement were collected and evaluated grossly and using light and electron microscopy.

\section{Results}

Grossly visible lesions (seen in 31/50) were classified as global $(16 / 50)$ or regional $(34 / 50)$. Global lesions were diffuse swelling and diffuse cerebral congestion or pallor. Multifocal petechial haemorrhages and white matter malacia appeared more regional. There were $18 / 50$ cases that had a grossly appreciable oedema. Histological lesions appeared in a spectrum of severity, and included very localized endothelial injury. Babesia-parasitised red cell sequestration was a feature in some sections. Early lesions were multifocal and strictly associated with the microvasculature. Intermediate lesions were characterized by perivascular haemorrhage and some neutrophil infiltration. Advanced lesions were locally extensive and similar in appearance to haemorrhagic infarction. Ultrastructural evidence of cytoadherence between erythrocytes and capillary endothelium was demonstrated. Endothelial cell necrosis occurred early in the development of the lesions before neuronal and glial changes.

\section{Conclusions}

The endothelial injury, parasitized red cell packing and perivascular haemorrhage showed some similarities to the neuropathology of human CM. However the large haemorrhagic infarctions and clinical presentation with almost $100 \%$ mortality of dogs presenting with cerebral babesiosis were key differences.

\section{Authors' details}

'Department of Companion Animal Clinical Studies, Faculty of Veterinary Science, University of Pretoria, Pretoria, 0110, South Africa. ${ }^{2}$ Mahidol Oxford Research Unit (MORU), Faculty of Tropical Medicine, Mahidol University, Bangkok 10400, Thailand. ${ }^{3}$ Department of Paraclinical Sciences, Faculty of Veterinary Science, University of Pretoria, Pretoria, 0110, South Africa.

Published: 22 September 2014

\section{References}

1. Craig AG, Grau GE, Janse C, Kazura JW, Milner D, Barnwell JW, Turner G, Langhorne J: The role of animal models for research on severe malaria. PLoS Pathog 2012, 8:e1002401.

2. Jacobson LS: The South African form of severe and complicated canine babesiosis: clinical advances 1994-2004. Vet Parasitol 2006, 138:126-139.

3. Aikawa M, Pongponratn E, Tegoshi T, Nakamura K, Nagatake T, Cochrane A, Ozaki LS: A study on the pathogenesis of human cerebral malaria and cerebral babesiosis. Mem Inst Oswaldo Cruz 1992, 87(Suppl 3):297-301.

doi:10.1186/1475-2875-13-S1-P55

Cite this article as: Leisewitz et al:: The neuropathology of canine cerebral babesiosis compared to human cerebral malaria. Malaria Journal 2014 13(Suppl 1):P55. 